SCIREA Journal of Environment

http://www.scirea.org/journal/Environmental

January 27, 2021

Volume 5, Issue 1, February 2021

\title{
From Science to Governance: Understanding global warming controversies and politicization in nine dates
}

\author{
KENFACK Chrislain Eric \\ Department of Political Science, University of Alberta, Canada \\ Email:kenfack@ualberta.ca
}

\begin{abstract}
The current global warming context is being experienced by world populations through the extreme whether events, sea level rise, loss of biodiversity, increase rise of temperature, reinsurgence of climate-related diseases and important slow and sudden-onset environmental catastrophes enhanced or accelerated by climate change among others. In such context, the global community, supported by evidenced science research are relentlessly calling for urgent climate actions to avoid reaching the point of non-return. Unfortunately, despite the fact that our planet continues to be under such threats of irreversible climate destruction, a fraction of scientists and political leaders motivated either by their nostalgic attachment to the carbondriven developmental era or pushed by the fossil fuel industry and its influential capacity on decision-making processes and decision-makers, continue to develop negationist theories, with the aim of creating skeptical mindsets and maintaining some doubts in public opinions as far as the very fact of global warming and the role of human activities in the occurrence of
\end{abstract}


such warming are concerned. In such controversial context, it is more than ever important to revisit the key drivers of the climate crisis, the historical path that led not only to the climate conscience building, but also and above all to its gradual politicization, and the key ideologies supporting the positions of both climate change defenders and climate-skeptics and deniers. This article, using a combination of bibliographic research and descriptive methodologies, intends to investigate that historical path and cover the resulting knowledge gap, through an ideology-based and chronical presentation of facts.

Keywords: Climate change, global warming history, climate politicization, climate consciousness, climate politics

The current global context is dominated by several crises among which one of the most important requiring pressing and urgent actions is global warming. Such global warming, it should be recalled, even though it can occur as a normal natural process is nevertheless enhanced and accelerated by human activities related to the industrial processes, the excessive dependency of coal, and the excessive exploitation and use of fossil fuel among others. Even though transiting from the current historically and progressively built pretroculture society to a post carbon society is today considered a necessity and a matter of emergency by the large majority of world populations and political leaders, the inaction, limited action or inadequacy of actions taken to combat global warming is today a matter of great concern. The questions that come to mind in this article are: which historical path led to the global consciousness of global warming? With the current level of shared climate change consciousness, what can really explain the limited action to combat it? Taking as postulate that one of the reasons of such inaction can be related to the controversies around the very fact or global warming or its origins, we can finally ask what ideologically sustain the positions of both climate defenders and climate skeptics or deniers? This aim of this article is to explore the above-enunciated interrogations and propose some initial responses. In order to do that, it is organized around three main axes: The first part is dedicated to the analysis of the key elements that help determine the earth climatic system and evaluate the occurrence of change in the global climate system. The second part focuses on the analysis of the historical path that progressively led to the global climate change consciences and politicization, 
whereas the last part dwells on the current key debates and controversies surrounding global warming.

\section{Research Methodology}

To gather the necessary data and proceed with the analysis of the historical path that led to the global consciousness of the climate threats and the gradual politicization of global warming, this article uses a combination of bibliographic research and descriptive methodologies, and presents its outputs in the form of ideology-base and chronological presentation of facts. The material used in this regard are mostly reports, published and unpublished relevant grey and scientific documents retrieved from libraries and electronic sources. Also, the research relied on reading materials obtained during various Massive Open Online Courses (MOOC) to which I undertook between 2011 and 2018 and that dealt with the multiple facets of climate change. The above materials include the training documents periodically produced by the United Nations Institute for Training and Research (UNITAR) on Climate Change Diplomacy, the training documents of the World Bank for its online training series on "Carbon trading" and on "tuning down the heat", as well as the material produced by the University of East Anglia for its course on climate justice. The access to web sources of the above-mentioned courses was facilitated by my participation to the courses, and the discriminative criteria that oriented my selection of reading materials was their relation to the study of the historical trajectory of global warming and global climate politics.

\section{Basic elements of the global climate system}

This section briefly reviews the various elements through which we can judge the effectiveness of global climate change. Thus, I analyze elements linked to temperature, rising sea levels, melting of ice, extreme weather events, as well as the threat to ecosystems and biodiversity.

\section{Temperature rise}

Current studies show a constant rise in global temperature. The average temperature in the northern hemisphere has been the highest in the last 50 years compared to the last 500 years. This upward trend in temperature also affects oceans that are exposed to warming up to 3000 meters. (Unitar, 2010a) This elevation is also observed at the polar level, and is considered to 
be at the same time the cause and the consequence of the melting of polar glaciers. According to a study done by NASA scientists Dwayne Brown, Michael Cabbage and Leslie McCarthy, the planet's average surface temperature has risen about 1.8 degrees Fahrenheit (1.0 degree Celsius) since the late-19th century, a change largely driven by increased carbon dioxide and other human-made emissions into the atmosphere. (Dwayne, Cabbage and McCarthy, 2016) Equally, following the data already available in 2009, the 10 warmest years since the start of observations in 1800 were between 1997 and 2008 (UNFPA, 2009), whereas in 2014 we have the 10 hottest years between 1998 and 2014. In early 2016, the 10 hottest years were reported to have been between 2006 and 2016, with 2015 being the hottest according to Figure 2 proposed by Climate central.

\begin{tabular}{|c|c|c|c|}
\hline $\begin{array}{c}\text { RANK } \\
1=\text { WARMEST } \\
\text { PERIOD OF RECORD: } 1880-2014\end{array}$ & YEAR & ANOMALY ${ }^{\circ} \mathrm{C}$ & ANOMALY ${ }^{\circ} F$ \\
\hline 1 & 2014 & 0.69 & 1.24 \\
\hline 2 (tie) & 2010 & 0.65 & 1.17 \\
\hline 2 (tie) & 2005 & 0.65 & 1.17 \\
\hline 4 & 1998 & 0.63 & 1.13 \\
\hline 5 (tie) & 2013 & 0.62 & 1.12 \\
\hline 5 (tie) & 2003 & 0.62 & 1.12 \\
\hline 7 & 2002 & 0.61 & 1.10 \\
\hline 8 & 2006 & 0.60 & 1.08 \\
\hline 9 (tie) & 2009 & 0.59 & 1.06 \\
\hline 9 (tie) & 2007 & 0.59 & 1.06 \\
\hline
\end{tabular}

Source : National Center for environmental information. 2014. "Global Analysis - Annual 2014" Available at: $\underline{\text { http://www.ncdc.noaa.gov/sotc/global/201413 (Retrieved on 19/10/2016) }}$ 


\section{TEN HOTTEST YEARS All Since 1998}

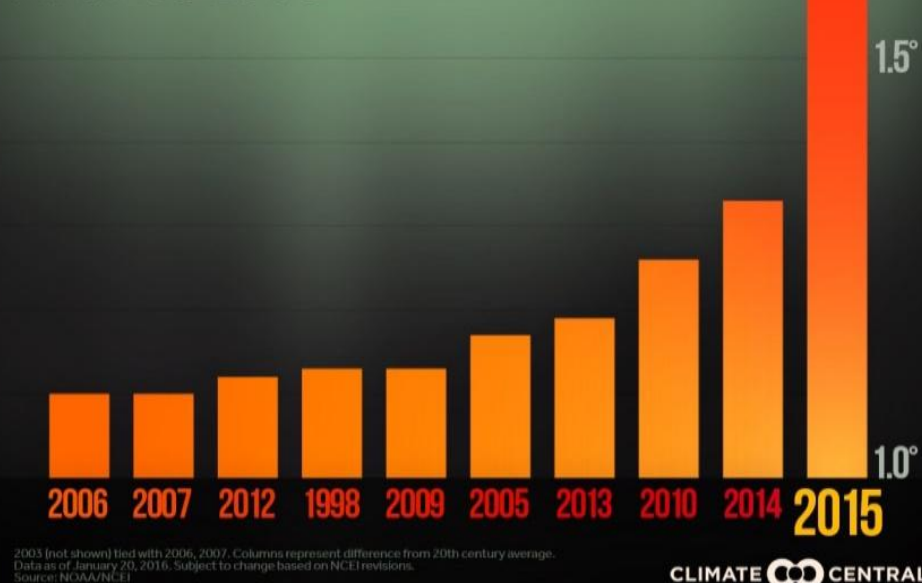

http://assets.climatecentral.org/images/uploads/gallery/2016GlobalNumbers TopTenYearsUpdate.i pg (Retrieved on 19/10/2016)

The below graph by the same Climate central displaying available data in 2018 shows that 2017 was the third warmest years on record, with 216 been the first and 2015 the second.

\section{HOTTEST YEARS GLOBALLY} TEMPERATURE ANOMALY $\left({ }^{\circ} \mathrm{F}\right)$

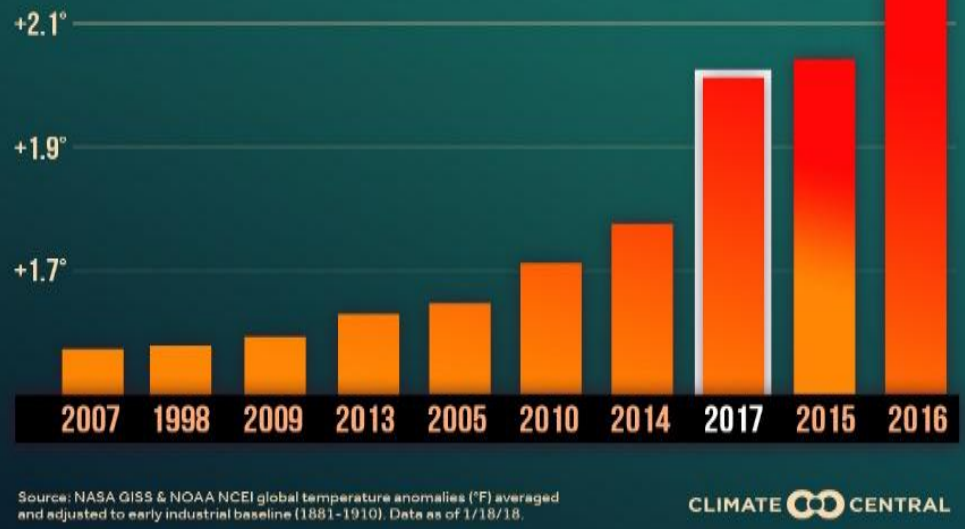

Source : Climate central. 2018. "The 10 Hottest Years on Record" Available at http://www.climatecentral.org/gallery/graphics/the-10-hottest-global-years-on-record (Retrieved on $14 / 09 / 2018$ ) 
The classifications of the hottest years as shown in the above table and the graphs are quite striking and demonstrate clearly that as years are passing, we are gearing toward a hotter environment, and global warming is following an undisputable increasing trend.

\section{Sea level rise}

Although in the course of history there has always been an increase in the level of the oceans as a result of natural mutation processes, such as the record level rise witnessed about 120,000 years ago which led to the transition from glacial to the solar era, and where the ocean level was about 5 to 6 times higher than today, the current rise is due not to mere natural processes, but to the overall rise in temperature. (Unitar, 2010a) This situation, it should be noted, is the result of the melting of glaciers, the increase in precipitation, and the human development activities which sometimes contribute to reducing the flow of water. Thus, "since 1961 global sea levels have been rising on average by 1.8 millimeters per year, and since 1993 this rate has accelerated by 3.1 millimeters per year. [...] The total global sea level rise that took place during the $20^{\text {th }}$ century amounted to 17 centimeters. The melting of glaciers, ice caps and Artic sea ice have contributed to this change." (Unitar, 2010a: 41-42) This continuous rise puts in danger not only the survival of Small Island States, but also influences the stability of the world climate.

\section{Melting of Snow and Ice}

One of the major components of global climate change is the melting of glaciers. Although the degree of loss is not yet evaluated in terms of figures, it is estimated that in the next few decades, if nothing is done, there is a possibility that a large lump of the Canadian northern region will disappear. This situation, which largely exposes polar regions, is nevertheless not limited to them. For example, the "eternal snow", that icy layer which covers Mount Kenya and which plays an important role in stabilizing the climate of the region has considerably melted since the 1970s. More to that, "decreases in the thickness and extent of snow and sea ice are also consistent with what would be expected as a result of the observed global temperature rise over past decades [as confirmed by climate modeling studies). Mountain glaciers and average snow cover have declined in both the Northern and Southern hemispheres." (Unitar, 2010a:43) This situation is all the more alarming as it already affects and will continue to affect life not only in the concerned milieus, but also and above all elsewhere on the planet. 


\section{Extreme weather events}

Extreme weather events are the face of global warming that is most visible and that affects the lives of millions of people on a daily basis around the globe. In recent decades, we have witnessed unpredictable violence and speedy atmospheric phenomena: Floods, long and repeated droughts in tropical and subtropical regions since the 1970s, (Unitar, 2010a) extreme temperatures, violent tornadoes, insect invasions and other predators plants whose life and development are made favorable by climate change, the scarcity of fresh days and nights for about 50 years now in favor of the multiplication of hot nights and days, the changes in the rhythm of the seasons, the reduction of rainfall in certain regions, while the same rainfall is constantly rising in other places, here are a few cases that help in measuring the magnitude of the situation. For example, it can be seen that "from 1900 to 2005, precipitations (rain, sleet and snow) increased significantly in parts of the Americas, northern Europe and northern and central Asia, but declined in the Sahel, the Mediterranean, southern Africa and parts of the Southern Asia." (Unitar, 2010a:43) Equally, according to NASA scientist Adam Voiland

There is medium confidence that some regions of the world have experienced more intense and longer droughts, in particular in southern Europe and West Africa, but in some regions droughts have become less frequent, less intense, or shorter, e.g., in central North America and northwestern Australia. There is evidence that some extremes have changed as a result of anthropogenic influences, including increases in atmospheric concentrations of greenhouse gases. It is likely that anthropogenic influences have led to warming of extreme daily minimum and maximum temperatures on the global scale. There is medium confidence that anthropogenic influences have contributed to intensification of extreme precipitation on the global scale. (Voiland, 2011)

These observations, among others, allow us to better notice the recurring extreme weather events that are characteristic of global warming.

\section{Ecosystems and biodiversity}

An ecosystem, it should be noted, is a natural unit made up of all the plants, animals and micro-organisms living in interrelation among them and with other living and non-living organisms. It is indeed all of these interrelations and interdependencies that constitute the essential part of an ecosystem. Biodiversity on the other side refers to the diversity of living 
beings on the surface of the earth, the sea and the air. It is in this respect that we will have a marine biodiversity, a faunal biodiversity, a floral biodiversity among others.

Current studies and observations show that many ecosystems are affected by global and regional climate change, especially as a result of rising temperatures and extreme rainfalls. This, on the other hand, affects and will continue to greatly affect living beings in these ecosystems, causing migrations and threatening the life of certain species. As such, currently approximately " $20-30 \%$ of species are estimated to be at increased risk of extinction should the global average warming exceed 1.5-2.5 $\mathrm{C}$ (from pre-industrial times). [...] Should the global average temperature increase exceed $3.5^{\circ} \mathrm{C}$, this will result in extinctions of $40-70 \%$ of known species around the globe." (Unitar, 2010a:56) All this is an invitation to have a new and more inquisitive look at the very reality of climate change and to a more controlled management of human-induced Greenhouse gases (GHGs) emissions that contribute or enhance the situation.

\section{Main greenhouse gases and their origin}

GHGs are natural gases present in the atmosphere and which main role is to stabilize the temperature of the planet to a level that allows life on earth. These gases therefore have an essential role in the equilibrium of global temperatures and climatic conditions. The most significant GHGs are water vapor $\left(\mathrm{H}_{2} \mathrm{O}\right)$, carbon dioxide $\left(\mathrm{CO}_{2}\right)$, methane $\left(\mathrm{CH}_{4}\right)$ and nitrous oxide $\left(\mathrm{N}_{2} \mathrm{O}\right)$ not only because of their quantity, but also and above all because of their direct influence on the earth climate system. (Lallanilla, 2015) All those gases are present in the atmosphere naturally, having an important role in stabilizing the temperature on the surface of the earth and rendering human, plants and animals' life possible. There are several other gases that contribute to the greenhouse effect. Most prominent among these are methane (CH4), nitrous oxide (N2O), ozone (O3), and chlorofluorocarbons, each of them being present in the atmosphere at a different concentration. It is nevertheless important to note that the most preoccupying gas is carbon dioxide, not only because it is the most produced by human activities, but also because it has a very long life cycle ${ }^{1}$, and consequently has a longer and deeper influence on the climate system than the other gases. However, despite this attention given to carbon dioxide, it is important to mention that the Kyoto Protocol draws

\footnotetext{
${ }^{1}$ Known as the carbon cycle, the lifetime of a carbon dioxide molecule is very long. During this lifetime which varies between centuries and millions of years, the molecule is transferred from one natural source or reservoir to another until its total degeneration.
} 
attention of the international community and of climate negotiators to a set of six GHGs, which atmospheric concentrations are worryingly increasing due to human activity. These gases include:

- $\quad$ Carbon dioxide $\left(\mathrm{CO}_{2}\right)$

- $\quad$ Methane $\left(\mathrm{CH}_{4}\right)$

- $\quad$ Nitrous oxide $\left(\mathrm{N}_{2} \mathrm{O}\right)$

- $\quad$ Hydrofluorocarbons (HFC)

- $\quad$ Perfluorocarbons (PFC)

- $\quad$ Sulfur hexafluoride $\left(\mathrm{SF}_{6}\right)^{2}$

The summarizing table below, without pretention of being exhaustive, presents the anthropogenic emissions of GHG considered under the Protocol and their sources.

\begin{tabular}{|c|c|}
\hline Greenhouse gases & Produced by \\
\hline Carbon dioxide & $\begin{array}{l}\text { Fossil fuel consumption, land clearing for } \\
\text { agriculture, cement production }\end{array}$ \\
\hline Methane & $\begin{array}{l}\text { Livestock Breeding, extraction of fossil } \\
\text { fuels, rice cultivation, landfills, waste water }\end{array}$ \\
\hline Nitrous oxide & Industrial processes, use of fertilizers \\
\hline \multicolumn{2}{|l|}{ Fluorinated gases } \\
\hline - $\quad$ Hydrofluorocarbons & $\begin{array}{l}\text { Leakages from refrigerators, aerosols, air } \\
\text { conditioners }\end{array}$ \\
\hline - $\quad$ Perfluorocarbons & $\begin{array}{l}\text { Production of aluminum, semiconductor } \\
\text { industry }\end{array}$ \\
\hline - $\quad$ Sulfur hexafluoride & Electrical insulation, magnesium melting \\
\hline
\end{tabular}

UNFPA, Etat de la population mondiale 2009, face à un monde qui change : les femmes, la population et le climat, New York, Fond des Nations Unies pour la population, 2009, P. 12

\footnotetext{
${ }^{2}$ Annex A of the "Kyoto Protocol to the United Nations Framework Convention on Climate Change." Available at http://unfccc.int/resource/docs/convkp/kpeng.pdf
} 


\section{How climate change became political: Nine dates to understand}

The history of the international climate consciousness and the need for urgent action is made up of several events. Nevertheless, for the purpose of this work, we will limit ourselves to the most significant ones, those that continue to have an impact on the current global warming debates and attempts to put in place global instrument for an effective fight.

\section{4: Discovery of the "greenhouse effect" phenomenon}

The theory of the greenhouse effect, which marks the starting point of the debate on the anthropogenic induced climate change is postulated for the first time in 1824 by Joseph Fourier who noted that "the temperature is augmented by the interposition of the atmosphere, because the heat has less trouble penetrating the air when it is in the form of light, than it has exiting back through the air after it has been converted to dark heat." (Fourier, 1824:13) Fourier, it must be noted based his analysis on the research of Horace Benedict de Saussure who, in the 1780s, measured the thermal effects of solar radiation with transparent boxes that he displayed in the valley and on the mountain top. This theory born in the world of physics and mathematics is certainly very complex, but we can understand it in a simple way through this description of Frédéric Guay:

Electromagnetic radiations from the sun collide the earth. The latter absorbs part of the emissions of these electromagnetic radiations, but it also retransmits part of it. Some gases present in the atmosphere intervene at that moment to absorb the energy emitted (reemitted) by the earth and reflects it in all directions, especially towards its point of origin, that is to say the very surface of the earth. These are the gases that cause the greenhouse phenomenon. Without these gases, it is estimated that the average temperature would have been between $18^{\circ} \mathrm{C}$ and $-8^{\circ} \mathrm{C}$. Under such weather conditions, the majority of organisms and ecosystems could not survive. (Guay, 1999:8) ${ }^{3}$

In clear, we can say that the earth receives energy from the sun in the form of ultraviolet, and visible or near-infrared radiations. Of the total amount of solar energy sent to earth, part (approximately $28.3 \%$ ) is directly reflected to the space by the air, the white clouds and the white surface of the earth, mostly the white and cold regions of the globe such as the Arctic and Antarctic; that is what is known as the albedo. The incident rays which were not reflected

\footnotetext{
3 Personal translation from French to English.
} 
back into the space (approximately 20.7\%) are absorbed by the atmosphere and the earth surface absorbs most of the remaining energy (51\%). This latter radiation absorbed by the surface of the earth brings heat, in other words the energy, to the earth under three different modalities. In the first moment that heat is reflected back to the atmosphere day and night in the form of far infrared rays. Secondly, this radiation is then absorbed in part by greenhouse gases, therefore warming the atmosphere. And thirdly, this heat is re-emitted in all directions; a portion escapes to the space, but another portion returns to earth and constitutes an additional supply of heat to the surface. (Guay, 1999; Kenfack, 2016)

\section{6: Hypothesis on the anthropogenic emissions of green GHGs}

This hypothesis was emitted for the first time by the Swedish scientist Auguste Arrhenius Svante in 1896. He was the first to make some calculations and to conclude that the doubling of the $\mathrm{CO}_{2}$ emissions will increase the average temperature of the earth between $4^{\circ} \mathrm{C}$ to $6^{\circ} \mathrm{C}$. (Guay, 1999) It is important to note that those figures still have their relevance in current climate modellings. It is equally important to mention that the work of Svantes was based on the analysis of John Tyndall who, in 1861, identified water vapor and carbon dioxide as the primarily responsible for the greenhouse effect, and who affirmed that a change in the composition of the atmosphere can have an influence on the evolution of the climate. As Enzler noted:

He [Svantes] proposed a relation between atmospheric carbon dioxide concentrations and temperature. He found that the average surface temperature of the earth is about $15^{\circ} \mathrm{C}$ because of the infrared absorption capacity of water vapor and carbon dioxide. This is called the natural greenhouse effect [...] He and Thomas Chamberlin calculated that human activities could warm the earth by adding carbon dioxide to the atmosphere. This research was a by-product of research of whether carbon dioxide would explain the causes of the great Ice Ages. (Enzler, 2015)

Going further in his calculations Chamberlin, quoted by Maslin (2014:24), concluded that "human activity could substantially warm the earth by adding carbon dioxide to the atmosphere." Nevertheless, such hypothesis of human-induced global warming will take more weight with the discovery of the Keeling curve and the establishment of the link between industrial emissions and rise in global temperatures. 


\section{8: Discovery of the Keeling Curve}

Charles David Keeling was born on the $20^{\text {th }}$ of April 1928 and died on the $20^{\text {th }}$ of June 2005. He was an American scientist whose measurements of the carbon dioxide at the Mauna Loa Observatory went beyond the hypothesis of Chamberlin and alerted the world on the anthropogenic contribution to the concentration of GHG and therefore to global warming. The Keeling curve is a graph that shows the progressive increase of carbon dioxide in the atmosphere. The curve, established in 1958, basically relied on the atmospheric carbon dioxide levels measured at Mauna Loa during the fifty previous years. As such, "Keeling used the most modern technology available to measure the concentration of atmospheric $\mathrm{CO}_{2}$ in Antarctica and Mauna Loa. The resulting Keeling $\mathrm{CO}_{2}$ curves have continued to climb ominously each year since the first measurement in 1958 and have become one of the major icons of global warming." (Maslin, 2014:26) In short, the data collection initiated by Keeling, and continued at Mauna Loa, is the longest continuous record of atmospheric carbon dioxide in the world and is considered a reliable indicator of the overall trend in the middle troposphere.

\section{2: United Nations Conference on Environment}

Following the constant warnings and appeals of the scientific community and the daily observations of climate change and its adverse effects on the society, the United Nations decided to organize a conference on the environment. Held from the $5^{\text {th }}$ to the $16^{\text {th }}$ June 1972 with the aim of striving "for a common outlook and for common principles to inspire and guide the peoples of the world in the preservation and enhancement of the human environment" (UNEP, 1972), that conference marked a decisive turning point in raising the international awareness on the urgency of climate change issues because, for the first time in history, the United Nations considered the matter and were therefore taking the first step to deal with it at the highest level. Equally, it is at that conference that the founding principle underlying the human right and duty with regards to the environment was set in the following terms: "Man has the fundamental right to freedom, equality and adequate conditions of life, in an environment of a quality that permits a life of dignity and well-being, and he bears a solemn responsibility to protect and improve the environment for present and future generations." (Idem.) Therefore, it is important to do everything possible and at all levels to save the environment that is largely threatened by global warming caused by anthropogenic 
activities of development and consumption. The conference, and the 26 articles report that it produced also insist on the importance of a responsible development as the only way of avoiding pollution and the exposure of our environment to irreversible dangers. Such report remains of astonishing relevance nowadays giving its contents, its warnings and its calls for strong measures to fight against human activities leading to environmental degradation.

\section{7: Publication of the Brundtland Report, "Our Common Future"}

The World Commission on Environment and Development, established in 1983 by the United Nations General Assembly, is an organization that maintains links with governments and the United Nations system, but remains independent in the fulfillment of its mandate. Its triple mission includes reviewing major environmental and development issues, proposing new modalities of cooperation that can bring about change, and raising the level of understanding and commitment of stakeholders with regards to those matters. The commission met for the first time in October 1984, and published its first report in April 1987. This report, based on the risks of climate catastrophes that are threatening our future and our planet, called for an urgent action to save the latter, in a new spirit of cooperation; because the future that is threatened is our common future. That is why:

The Commission's hope for the future is conditional on decisive political action now to begin managing environmental resources to ensure both sustainable human progress and human survival. We are not forecasting a future; we are serving a notice - an urgent notice based on the latest and best scientific evidence - that the time has come to take the decisions needed to secure the resources to sustain this and coming generations. We do not offer a detailed blueprint for action, but instead a pathway by which the peoples of the world may enlarge their spheres of cooperation. (World Commission on Environment and Development, 1987:11)

The report had a great impact both on the academic and political world, and marked a decisive blow in the international awareness of climate risks and the urgency for a concerted action in the fight against global climate change. 


\section{8: Creation of the Intergovernmental Panel on Climate Change (IPCC)}

The creation of the IPCC marked a major milestone in the introduction of scientific understanding and involvement in the attempts to resolve the global environmental crisis by the international community. In fact, taking into account the seriousness of the global climate change problem, the World Meteorological Organization (WMO) and the United Nations Environment Program (UNEP) put in place the IPCC in 1988. The IPCC is therefore an intergovernmental body opened to all $\mathrm{UN}$ and WMO member countries and its secretariat is located in Geneva in the premises of WMO. Its main mission is to assess in an unbiased and methodical, clear and objective way the scientific, technical and socioeconomic information relevant for understanding the risks linked to anthropogenic induced climate change, and to identify more precisely the possible consequences of change, while equally considering adaptation and mitigation strategies. It simply works on the basis of available knowledge on climate change, based on scientific journals, publications and other authoritative sources of scientific, technical and socio-economic research from a multidisciplinary perspective, and has no mandate to undertake new research. (Unitar, 2010b) To date, the IPCC has produced five evaluation reports in which, in a very progressive way, it recognizes the anthropogenic origin of global warming, urges for action, and shapes the consciousness of the international community in that regard as follow:

- In 1990 the first report acknowledged that through the various observations we can conclude on unambiguous increase in the greenhouse effect is in the next few decades or more, and it proceeded by calling for a united approach in tackling the problem.

- In 1995, a new report led to the Kyoto Protocol. The report went further and officially acknowledged the role of human activities in the following terms: "the study of evidences suggests a detectable influence of human activity on the global climate."

- In 2001, with the third report, The IPCC increased its conviction on the role of human activities in enhancing the global warming. In fact, according to the report, "there is strong evidence that the global warming trend over the last fifty years is attributable to human activity." And it went on proposing measure to limit the GHG emissions.

- In 2007, the fourth IPCC report concluded that most of the observed increase in global average temperature since the mid-20th century is "very likely" due to the observed increase in GHGs emitted by man. The degree of certainty is higher than $90 \%$, compared to $66 \%$ in 2001 . 
- In 2014, the fifth GIES report concluded that despite the multitude of actions and mitigation projects carried out around the world, the pace of GHG emissions has accelerated in recent decades. According to this report, anthropogenic GHG emissions have increased since the pre-industrial era, largely because of economic and demographic growth, and are now higher than ever before. These emissions have led to atmospheric concentrations of carbon dioxide, methane and nitrous oxide which have been unprecedented for the past 800,000 years. Their effects, as well as those of other anthropogenic drivers, have been detected throughout the climate system and are extremely likely to have been the dominant cause of the warming observed since the mid- $20^{\text {th }}$ century

After the publication of those five reports, another special report on climate change, oceans and the cryosphere is being prepared under the joint scientific leadership of Working Groups I, II and III of the IPCC.

\section{2: Adoption of the United Nations Framework Convention on Climate Change (UNFCCC)}

Adopted in New York in the United States on May $9^{\text {th }} 1992$, this convention is the first international consultation instrument set up by States, in the context of the current fight against global climate change. It is made up of 26 articles and 2 annexes (I and II), and is, so far, the basic framework that supports and guides international climate negotiations. Its main objective is to encourage countries to act. To be legitimately and legally considered party to the convention, two conditions need to be fulfilled: Be a State or a regional Organization of economic integration and secondly be a signatory to the convention and have already deposited the ratification instrument. According to Article 51,

The Convention shall be subject to ratification, acceptance, approval or accession by States and by regional economic integration organizations. It shall be open for accession from the day after the date on which the Convention is closed for signature. Instruments of ratification, acceptance, approval or accession shall be deposited with the Depositary (UNFCCC, 1992).

The Depository of the convention, in this context is the UN secretariat, and the Secretariat that is in charge of preparing global climate negotiations under the banner of the UN is situated in Bonn. Currently, there are 197 Parties (196 States and 1 regional economic integration organization) to the UNFCCC. 


\section{7: Adoption of the Kyoto Protocol to the United Nations Framework Convention on}

\section{Climate Change}

Adopted in Kyoto, Japan on $11^{\text {th }}$ December 1997, this protocol of 28 clauses and two annexes ( $\mathrm{A}$ and $\mathrm{B}$ ) is the first legal binding instrument conceived by the international community to fight against climate change. The protocol played a significant role in shaping and articulating the relation between the global fight against climate change and the global capitalist market, through its conception and implementation of market mechanisms also known as "flexible mechanisms". Initially three in number namely the International Emission Trading (IET), the Clean Development Mechanism (CDM) and the Join Implementation (JI), those market mechanisms will be increased under the Bali Roadmap by the Reduction of Emissions due to Deforestation and forest Degradation (REDD) mechanism and with the Paris Agreement by the Internationally Transferred Mitigation Outcomes (ITMOs). Through such market-oriented solution seeking the Kyoto protocol initiated the current dominant line of global climate policies and public actions that seem to be presented by the global climate decision-makers as the only way forward. The protocol is binding in nature and contains quantified GHG reduction targets for developed countries, and its initial lifespan is limited to 2012. However, with the failure of negotiations to set up a replacement agreement in Copenhagen in 2009, a transitional period was granted, in the hope that the Parties would reach a consensus at COP 21 in Paris, France in 2015. Nevertheless, with the adoption of the Paris Agreement on the $12^{\text {th }}$ December 2015 and especially its entry into force in 2020, the future of the Kyoto Protocol remains uncertain, especially because none of the provisions of the Paris Agreement abrogates the Kyoto Protocol. (Kenfack, 2016) Currently, there are 192 Parties (191 States and 1 regional economic integration organization) to the Kyoto Protocol.

\section{5: Adoption of the Paris Agreement: “Another legal Instrument”}

According to the Durban Platform for Enhanced Action (decision 1/CP.17), the mission of the Paris negotiations was not to build a Post- Kyoto agreement (contrary to what is often said and defended), but to lead to the "adoption of a protocol, another legal instrument, or an agreed outcome with legal force under the Convention applicable to all Parties." that, as we mentioned above, no disposition in the agreement abrogates the Kyoto Protocol, or any of its mechanisms. Instead, through its eight invocation of the Kyoto Protocol, the

\footnotetext{
${ }^{4}$ Cf. Decision 1/CP17: Establishment of an Ad Hoc Working Group on the Durban Platform for Enhanced Action, FCCC /CP/2011/9/Add.1, 15 March 2012.
} 
Paris Agreements sees itself as a continuity or an enhancement of Kyoto. This demonstrate that, in the strict legal sense, with the entry in force of the Paris agreement, the international climate arena will be led by three texts, namely: The UNFCCC and its two additional protocols (the Kyoto Protocol and the Paris Agreement), which will cohabit in modalities still to be discovered. Such cohabitation will also concern the market mechanisms set by the two additional instruments of the UNFCCC.

In fact, from the $30^{\text {th }}$ November to the $12^{\text {th }}$ December 2015, world leaders and countries delegations gathered in Paris, France for the $21^{\text {st }}$ session of the conference of the parties to the UNFCCC. Following the drastic failure of the 2009 conference in Copenhagen, and the 2011 conference in Durban that mandated the COP 21 to put in place another legal binding instrument to fight global warming, negotiators of the Paris conference had the mission of putting such instrument in place. As such, initially expected to end on the $11^{\text {th }}$, the conference finally took an additional day in order to give negotiators the possibility of agreeing on the last details of the agreement before presenting it to the world. Made up of a preamble of 140 points going from page 1 to 19 , and an annex containing 29 articles and going from page 20 to 31 , the document was consensually accepted by all the negotiators of COP 21 , after a thorough discussion on its content and a meticulous choice of terms to be included. According to article 20 paragraph 1, the "agreement shall be open for signature and subject to ratification, acceptance or approval by States and regional economic integration organizations that are parties to the convention. It shall be open for signature at the United Nations Headquarters in New York from 22 April 2016 to 21 April 2017." ${ }^{5}$ The agreement, due to enter into force in 2020 (European Commission, 2015), aims at "enhancing the implementation of the convention, including its objective [and] to strengthen the global response to the threat of climate change." (UNFCCC, 2015:Article 2) From a procedural point of view one of the originality of the Paris climate summit is the institutionalization of the Countries' Intended Nationally Determined Contributions (INDC) ${ }^{6}$ Through this

\footnotetext{
${ }^{5}$ During the official ceremony to open the agreement for signature at the Headquarters of the UN in New York, 175 parties signed it, and 15 States deposited their instrument of ratification. Of the 175 parties, there were 174 countries and the European Union (only Regional Organization of Economic integration party to the UNFCCC). Currently the agreement has been signed by 197 parties. Of the 197 parties, 181 have already deposited their instruments of ratification. The "agreement entered into force on 4 November 2016, thirty days after the date on which at least 55 Parties to the convention accounting in total for at least an estimated $55 \%$ of the total global greenhouse gas emissions have deposited their instruments of ratification, acceptance, approval or accession with the Depositary." (UNFCCC 2016)

${ }^{6}$ In preparation of the Paris COP 21, countries agreed to clearly outline and render public what post-2020 climate actions they intend to take under a new international agreement. These contributions were
} 
orientation, the international community of climate decision-makers mandates the future of climate politics and actions to States under the coordination and control of the Conference of the Parties, and institutes a bottom-up approach in global climate governance. In this new configuration countries make their reduction pledges and the international community only relies on the naming and shaming tactic to encourage action (Busby 2016; Ivanova 2016; Falkner 2016, Morgan, 2016).

Nevertheless, it should be noted, such progressive global climate consciousness and the respective political actions have always and continue to be take place amidst controversies surrounding global warming.

\section{Global warming: Debates and controversies on regimes and origins}

If scientists are unanimous on the present climate changes phenomenon, they are less so about the characterization of the climate regime in which we find ourselves, and the origin of the problem. It is to try to understand this reality that in this section I will focus on the terminological differences that substantiate the positions of climate defenders and sceptics or deniers, and I will proceed by clarifying the very origin of the GHG that are the driving factors of the climate problem.

\section{Terminological debates on climate regimes}

The debates on the current climate regime lead us to identify three fundamental trends: the oscillation regime, the regime of variations, and the regime of change.

\section{The oscillation regime ${ }^{7}$}

determined by each country, taking into consideration its national priorities, circumstances and capabilities, and were submitted to the secretariat of the UNFCCC prior to the beginning of the COP 21.

${ }^{7}$ It should be noted that this vision, as well as the regime of variation, is that of most corporate scientists of the fossil fuel industry and other climate sceptics and climate deniers led by Jean Christophe Klein, Peter Scott, Knud Lassen and Roy Spencer among others, mostly base their arguments in this tendency. It is their studies and views, coupled to the widely spread climate skepticism in the USA that have shaped not only US public opinion, but even more orient the US position in negotiations and global policies against climate change. At the European level this tendency is not absent. According to the president of the European Chemical Society, István Markó for example, in an interview in 2011 declared "We know very little about the Earth's climate, and the IPCC statements are used for political purposes. [...] Moreover, to assert that the rate of $\mathrm{CO} 2$ increases the temperature of the globe is erroneous. The rise in temperature precedes the increase in $\mathrm{CO} 2$ [...] It is therefore scientifically reasonable to ask whether it is worth investing such a large amount of money and jeopardizing 
Climatic oscillations are often referred to when the available data cover a period of less than 30 years. Those who opt for this view believe that the changes observed in the global climate are not long and therefore it is too early to talk of climate change. Relying on historical phenomena such as the heat wave that humanity experienced around the 1970s and that lasted for almost a decade, the defenders of the oscillation regime think that it is still necessary to take the necessary time to better observe before drawing conclusions. They feel that the tenors of climate change are a little too alarmist about the situation for nothing. (Kenfack, 2016) They also claim that human activities have no influence on the climate regime, and that human is in no sense responsible of the current global warming that humanity is experiencing. That is why they also advocate that we do not have to take any specific action since we are not responsible, and cannot change anything by our political measures.

\section{The regime of variations}

The defenders of this regime think from the double perspective of variation and variability. We speak of climatic variation when we talk about a variability of atmospheric conditions over a period of 30 years and more. The variability is understood as the difference between the average temperature and the mutation considered, regardless of the duration. However, when this variability is less than 30 years, it is not possible to speak of climatic variations. This variability may be regional or global, downward or upward alternately. This tendency is the most widespread in the scientific world, mostly among those dealing with climate models and modellings. According to the defenders of this regime, available studies show that climate change is not unilateral, and modeling tests generally show that climate change, "scientifically speaking", will only be possible from years 2100. (Kenfack, 2016) It is therefore wiser to consider the climate issue, scientifically speaking, under the regime of variation, if we want to keep to the available data and models. In fact, climate change is always evoked in terms of future possibilities, above all if nothing is done now to prevent it (Kenfack, 2015). Just to say, from this perspective, at the present moment climate change is more a matter of modelling than a reality.

our industries and Our societies, for a result that we do not know how to attain [...] The best thing for science is that we are allowed to work calmly and without bias on the evolution of Our knowledge and that we are being led to believe that "the debate is closed" 


\section{The regime of change}

As for the regime of change, it should be noted that global warming is perceived both as a real danger (a danger that is experienced here and now and that is being faced by people in real time), and as a potential danger (that is a danger not yet present but which will occur over time, according to climate modeling and predictions). Just like in the case of variations, climate change is assessed through data which observation goes beyond 30 years, but with a continuous upward trend. So, if during the period concerned there is stabilization or decrease in temperature, we will no longer speak of climate change but of climatic variation. However, this trend is predominant in climate discourses and policies; this can be explained by the fact that it is this vision that has been endorsed by the scientists of IPCC and is therefore used in all international documents and global negotiations on climate change. (Kenfack, 2016) It is this terminology that $\mathrm{I}$ use in this article, in order to align myself to the vocabulary in force in the international community and generally used by the scientific community on the one hand and, on the other hand, not to sink into the internal terminological debates of climatologists. The climate change terminology enjoys a certain international unanimity, an interdisciplinary and transversality, and consequently is more appropriate in this context.

\section{Controversies on the Origin of Climate Change: A brief overview}

The issue of the origin of global climate change is of paramount importance and raises a lot of debates. However, it is important to note that all those debates revolve around two major trends the positions of defending actors namely: climate change as a result of natural cycles' mutations according to climate sceptics and deniers, and climate change as a result of human activities for climate change defenders.

\section{Climate change and natural cycles}

First of all, it is important to mention that climate change mutations are an integral part of the cyclical functioning of nature. Their occurrence is not primarily the result of an exogenous action, but it is endogenous to the natural order. In this regard, the disappearance of dinosaurs in prehistory is attributed to climatic changes, manifested by an unparalleled cooling of the planet which at that time was due to the fall of meteorites on the surface of the terrestrial globe. In addition, the history of mankind, before the great industrial era, experienced climatic changes that were due to the simple internal logic of natural cycles because the 
planetary system operates at a cyclical rhythm which, for endogenous reasons, can be changed at one time or another. According to the NASA,

In Earth's history before the Industrial Revolution, Earth's climate changed due to natural causes not related to human activity. Most often, global climate has changed because of variations in sunlight. Tiny wobbles in Earth's orbit altered when and where sunlight falls on Earth's surface. Variations in the Sun itself have alternately increased and decreased the amount of solar energy reaching Earth. Volcanic eruptions have generated particles that reflect sunlight, brightening the planet and cooling the climate. Volcanic activity has also, in the deep past, increased greenhouse gases over millions of years, contributing to episodes of global warming ${ }^{8}$

Indeed, Unitar clarifies this reality in the following terms:

The conditions of the climate system evolve over time under the influence of the changes within its own internal (energy) dynamics and also due to changes in external factors that influence the overall energy balance of Earth's systems (Called external forcings). External forcings include natural phenomena such as volcanic eruptions and variability in the sun's radiative output, as well as changes in the concentration of greenhouse gases. (Unitar, 2010a:16)

Maslin (2014:19) goes in the same line when believes that "the cooling that occurred globally during the 1970s was unexplained until the 'external' and cyclic variations every 11 years in the sun's energy output, the so-called sunspot cycle, was taken into consideration." Following this logic and going beyond all other strategic, economic and financial interests, we can understand, without justifying, the skepticism of those who do not yet fully accept that the current climatic change has a different origin than that linked to the normal functioning of nature which, according to its whims, varies sometimes. (Kenfack, 2016) However, the relatively rapid rate of climate change prompts us to questions ourselves about the truly natural origin of such change, since mutations that in the course of history have always occurred at very large intervals and were often related to known phenomena, occur nowadays in the space of a few years, or even of a few decades at most, and without being provoked by anything precise, except the parallel increase of anthropogenic GHGs emissions in the atmosphere since the beginning of the industrial era.

\footnotetext{
${ }^{8}$ For further analysis, refer to NASA. "Is Current Warming Natural?" Available at http://earthobservatory.nasa.gov/Features/GlobalWarming/page4.php (Retrieved on 15/11/2016)
} 


\section{Climate change and anthropogenic activities}

The anthropogenic origin seems to be, as far as the climate issue in general is concerned, the only meeting point and quasi-unanimity of scientists. This is due to the fact that the most accurate observations and studies in this field link climate change to the increase in the concentration of GHGs in the atmosphere; Concentration caused by the large-scale use of fossil fuels for industrialization, transportations, agriculture and deforestation among others. In fact, since 2.5 million years the temperature of the earth knows fluctuations, going from ice ages to hot periods. But during the last centuries the temperature of the planet rose unusually, and evidences show that human activities are causing this increase. Since the beginning of the industrial revolution, industries, energy plants and possibly cars, and other human related activities of production, consumption and waste disposal have contributed in emitting large amounts of carbon dioxide and other gases into the atmosphere. If we consider some few cases, we can easily conclude with the IPCC that:

Human activities result in emissions of four principal greenhouse gases: carbon dioxide (CO2), methane (CH4), nitrous oxide $(\mathrm{N} 2 \mathrm{O})$ and the halocarbons (a group of gases containing fluorine, chlorine and bromine). These gases accumulate in the atmosphere, causing concentrations to increase with time. Significant increases in all of these gases have occurred in the industrial era (see Figure 1). All of these increases are attributable to human activities.

- Carbon dioxide has increased from fossil fuel use in transportation, building heating and cooling and the manufacture of cement and other goods. Deforestation releases CO2 and reduces its uptake by plants. Carbon dioxide is also released in natural processes such as the decay of plant matter.

- Methane has increased as a result of human activities related to agriculture, natural gas distribution and landfills. Methane is also released from natural processes that occur, for example, in wetlands. Methane concentrations are not currently increasing in the atmosphere because growth rates decreased over the last two decades.

- Nitrous oxide is also emitted by human activities such as fertilizer use and fossil fuel burning. Natural processes in soils and the oceans also release N2O.

- Halocarbon gas concentrations have increased primarily due to human activities. Natural processes are also a small source. Principal halocarbons include the chlorofluorocarbons (e.g., CFC-11 and CFC-12), which were used extensively as refrigeration agents and in other 
industrial processes before their presence in the atmosphere was found to cause stratospheric ozone depletion. The abundance of chlorofluorocarbon gases is decreasing as a result of international regulations designed to protect the ozone layer. (IPCC, 2007:100)

Just to say that if we have arrived at the present situation, it is mainly because of human activities that, through the production and emission of GHGs, have contributed in increasing the atmospheric concentration of these same gases, thus modifying the atmospheric capacity to function according to its natural rhythm and its resilience capacity. It is for this reason that the current general trend is to consider the role of anthropogenic emissions in all research, negotiations and global attempts to combat climate change.

\section{Conclusion}

In short, as we can see, the climate change phenomenon is an integral part of the normal functioning and evolution of natural systems. However, the current responsibility for climate change is attributed to humans because scientific observations and research demonstrates that the current global temperature rise is a consequence of the increase of atmospheric of GHGs resulting from the processes of industrialization, consumption and waste disposal conducted by humans from the beginning of the industrial era. It is in this perspective that, as a result of the constant appeals of the scientific community, the world in general and political decisionmakers in particular have gradually become aware of the phenomenon and the need for urgent action, despite all the controversies and debates surrounding the climate issue.

\section{References}

[1] Busby J. 2016. “After Paris: Good Enough Climate Governance.” Current History 19:39

[2] Climate central. 2016. "The 10 Hottest Years on Record" Available at http://assets.climatecentral.org/images/uploads/gallery/2016GlobalNumbers_TopTenYea rsUpdate.jpg (Retrieved on 19/10/2016)

[3] Climate central. 2018. "The 10 Hottest Years on Record" Available at http://www.climatecentral.org/gallery/graphics/the-10-hottest-global-years-on-record (Retrieved on 14/09/2018) 
[4] Dwayne B., Cabbage M. and McCarthy L. 2016. "NASA, NOAA Analyses Reveal Record-Shattering Global Warm Temperatures in 2015”. Available at https://www.nasa.gov/press-release/nasa-noaa-analyses-reveal-record-shattering-globalwarm-temperatures-in-2015 (Retrieved on 19/10/2016)

[5] Enzler S.M. 2015. "History of the greenhouse effect and global warming

[6] Available at: https://www.lenntech.com/greenhouse-effect/global-warminghistory.htm\#ixzz5T3zESO17 (Retrieved on 19/10/2016)

[7] European Commission. 2015. "Paris Agreement" Available at: http://ec.europa.eu/clima/policies/international/negotiations/paris/index_en.htm

[8] Falkner R. 2016. "The Paris Agreement and the new logic of international climate politics.” International Affairs 92(5):1107-1125

[9] Fourier J.-B. J. 1824. "Remarques générales sur les températures du globe terrestre et des espaces planétaires.” Annales de Chimie et de Physique 2(XXVII) :136-167

[10] Guay F. Impacts de la réduction des émissions de gaz a effet de serre sur la compétitivité de l'industrie nord-américaine des pâtes et papiers, Mémoire présenté à la Faculté des études supérieures de 1'Université Laval pour l'obtention du grade de maître ès arts (M. A.), Novembre 1999. Available at www.nlc-bnc.ca/obj/s4/f2/ dsk1/ tape7/ PQDO_ 0016/MQ47208.pdf

[11] IPCC. 2007. "Climate Change 2007: Working Group I: The Physical Science Basis." Contribution of Working Group I to the Fourth Assessment Report of the Intergovernmental Panel on Climate Change." In IPCC Fourth Assessment Report: Climate Change 2007. Cambridge University Press, Cambridge and New York. Available

at https://www.ipcc.ch/publications_and_data/publications_ipcc_fourth_assessment_report _wg1_report_the_physical_science_basis.htm

[12] Ivanova M. 2016. “Good COP, Bad COP: Climate Reality after Paris.” Global Policy 7(3):411-419

[13] Kenfack C. E. 2015. "Changements climatiques et droits humains fondamentaux: Vers une climatopolitique anthropocentrée." In Mahktar Kante A. (Dir.) Environnement, changeme.nt climatique et sécurité alimentaire en Afrique de l'Ouest et du Centre: compréhension des enjeux et pistes pour l'avenir. CODERIA. Dakar. PP. $37-$ 64 
[14] Kenfack C.E. 2016. Vulnérabilité et enjeux climatiques internationaux: De la climatopolitique internationale aux droits de l'Homme. Edition Connaissances et Savoirs. Saint-Denis

[15] Lallanilla M. 2015. "Greenhouse Gas Emissions: Causes \& Sources" Available at http://www.un-documents.net/our-common-future.pdf

[16] Maslin M. 2014. Climate Change: A Very Short Introduction. Oxford University Press. Oxford

[17] Morgan J. 2016. "Paris COP 21: Power that Speaks the Truth?" Globalizations 13:943951

[18] NASA. "Is Current Warming Natural?" Available at http://earthobservatory.nasa.gov/Features/GlobalWarming/page4.php (Retrieved on $15 / 11 / 2016)$

[19] National Center for environmental information. 2014. "Global Analysis - Annual 2014" Available at: http://www.ncdc.noaa.gov/sotc/global/201413 (Retrieved on 19/10/2016)

[20] UNEP. 1972. "Declaration of the United Nations Conference on the Human Environment". Available at http://www.un-documents.net/unchedec.htm

[21] UNFCCC. 1992. "United Nations Framework Convention on Climate Change" Available at https://unfccc.int/sites/default/files/conveng.pdf

[22] UNFCCC. 1998. "Kyoto Protocol to the United Nations Framework Convention on Climate Change" Available at https://unfccc.int/resource/docs/convkp/kpeng.pdf

[23] UNFCCC. 2009. FCCC/AWGLCA/2009/8. Negotiating text. Document prepared by the Ad Hoc Working Group on Long-term Cooperative Action under the Convention (AWG-LCA). Available at http://unfccc.int/resource/docs/2009/awglca6/eng/08.pdf

[24] UNFCCC. 2012. "Decision 1/CP17: Establishment of an Ad Hoc Working Group on the Durban Platform for Enhanced Action, FCCC /CP/2011/9/Add.1" Available at https://unfccc.int/resource/docs/2011/cop17/eng/09a01.pdf

[25] UNFCCC. 2012. Decision 1/CP17: Establishment of an Ad Hoc Working Group on the Durban Platform for Enhanced Action, FCCC /CP/2011/9/Add.1, 15 March 2012.

[26] UNFCCC. 2015. "Adoption of the Paris Agreement." Available at: http://unfecc.int/resource/docs/2015/cop21/eng/109r01.pdf

[27] UNFCCC. 2016. "Paris Agreement - Status of Ratification." Available at https://unfccc.int/process/the-paris-agreement/status-of-ratification 
[28] UNFPA. 2009. Etat de la population mondiale 2009, face à un monde qui change : les femmes, la population et le climat. Fond des Nations Unies pour la population. New York

[29] Unitar. 2010a. Understanding climate change and global vulnerability. module I. Coll. climate change diplomacy. Available at wwwunitar.org/mdp

[30] Unitar. 2010b. Introduction to climate change diplomacy. module II. Coll. climate change diplomacy. Available at www.unitar.org/mdp

[31] Voiland A. 2011. "To What Degree is Extreme Weather Linked to Climate Change?" Available at https://blogs.nasa.gov/whatonearth/2011/12/06/post_1321896724591/

[32] World Commission on Environment and Development. 1987. "Report of the World Commission on Environment and Development: Our Common Future". Available at http://www.un-documents.net/our-common-future.pdf 